\title{
Astigmatism and visual recovery after phacoemulsification and conventional extracapsular cataract extraction
}

\author{
NICOLE C. NAUS, GREGORIUS P. M. LUYTEN, THEO STIJNEN \& \\ PAUL T. V. M. DE JONG \\ Department of Ophthalmology, University Hospital Rotterdam, The Netherlands
}

Accepted 16 October 1994

Key words: Astigmatism, Visual recovery, Phacoemulsification, Extracapsular cataract extraction

\begin{abstract}
In this study we wanted to investigate the post-operative astigmatism and visual acuity after phacoemulsification and conventional extracapsular cataract surgery. Patients operated between April and June $1993(n=150)$ were retrospectively analyzed. The patients were examined prior to surgery and at day 1 , at day 10 , and in week 6 post-operatively. The difference between the post-operative $\log$ mean visual acuity in the Phaco group and in the CECCE group was significant after 1 and 10 days, however it was not significant $(p=0.191)$ after 6 weeks. The mean astigmatism was significantly less in the Phaco group than in the CECCE group during the whole post-operative check-up period. This study suggests that Phaco results in a lower post-operative astigmatism and an earlier visual rehabilitation compared to the CECCE technique.
\end{abstract}

Abbreviations: Phaco-Phacoemulsification; CECCE-Conventional extracapsular cataract extraction.

\section{Introduction}

With the introduction of small-incision cataract extraction with phacoemulsification, it was suggested that patients had a shorter post-operative recovery of the visual acuity and post-operative astigmatism using this technique [1, 2].

In this study, the described advantage of the small incision cataract extraction with the phacoemulsification was assessed by comparing the visual rehabilitation and post-operative astigmatism in a group of cataract patients operated with the CECCE technique with a group of patients operated with Phaco.

Secondly, with the use of echographic biometry of the operated eye, an emmetropizing intraocular lens can be planned [3,4]. Analysis of systematic errors in ultrasonic biometry results in a 25 to $30 \%$ post-operative refractive 
error of more than $1 \mathrm{D}$. In about $5 \%$ of the cases it results in more than $2 \mathrm{D}$ refractive error [3].

In this investigation, we studied the effects on the refractive errors resulting from our biometrical calculations for the emmetropizing intraocular lenses.

\section{Patients and methods}

Patients. In a retrospective study, cataract patients operated between April and June $1993(n=150)$ were analyzed. The cataract extractions were performed by experienced surgeons as well as residents in training. Furthermore patients with both complicated and uncomplicated cataract extractions were included in this study. The cataract extractions with intraocular lens implantation were done with the conventional extracapsular technique (CECCE group) or with the phacoemulsification technique (Phaco group) depending on the experience of the surgeon.

Surgical procedures. A standard phacoemusification procedure was used through a $3.2 \mathrm{~mm}$ bevelled two-step tunnel-incision about $1 \mathrm{~mm}$ posterior to the superior corneoscleral limbus. Following phacoemulsification of the nucleus, aspiration of the residual cortex, and the implantation of an intraocular lens with an optic of $5.5 \mathrm{~mm}$ or $6.5 \mathrm{~mm}$, the wound was closed with an uninterrupted 10.0 monofilament nylon suture (Alcon Surgical, Fort Worth, Texas). For the standard extracapsular technique a bevelled corneoscleral incision of 12 to $13 \mathrm{~mm}$ in length was made, a $6.5 \mathrm{~mm}$ intraocular lens was implanted in the bag and the wound was closed by an uninterrupted suture of 10.0 nylon.

Post-operative astigmatism and visual acuity. Pre-operatively, the visual acuity and refraction were measured for all patients. On day 1 , day 10 and after 6 weeks the post-operative astigmatism, refraction and visual acuity were examined when these data were available. These parameters were studied for the CECCE and the Phaco group.

Refractive error. The effect on the refractive error from the emmetropizing power of the intraocular lenses were studied by comparing the predicted refractive power with the post-operatively resulting refractive power. The average difference between the predicted and resulting refractive power were subdivided by axial length. 
Table 1. The (log) mean pre- and post-operative visual acuity in the Phaco and CECCE group

\begin{tabular}{llll}
\hline & Phaco (n) & CECCE (n) & $p$-value \\
\hline Pre-operative & $0.210(116)$ & $0.087(33)$ & 0.006 \\
Day 1 & $0.401(94)$ & $0.244(29)$ & 0.013 \\
Day 10 & $0.544(107)$ & $0.343(30)$ & 0.001 \\
Week 6 & $0.629(82)$ & $0.382(27)$ & 0.022 \\
\hline
\end{tabular}

Table 2. The (log) mean pre- and post-operative visual acuity in the Phaco and CECCE group after selection of patients with a pre-operative visual acuity $>0.1$

\begin{tabular}{llll}
\hline & Phaco (n) & CECCE (n) & $p$-value \\
\hline Pre-operative & $0.320(99)$ & $0.283(19)$ & 0.271 \\
Day 1 & $0.489(79)$ & $0.310(18)$ & 0.020 \\
Day 10 & $0.628(92)$ & $0.378(17)$ & 0.015 \\
Week 6 & $0.736(70)$ & $0.520(13)$ & 0.191 \\
\hline
\end{tabular}

Statistical analysis. The student's two sample t-test was used to assess the statistical significance of the differences between the CECCE and the Phaco group in astigmatism and log mean visual acuity [5] at various post-operative time intervals.

\section{Results}

Phaco and CECCE. One hundred and fifty patients (eyes) were included in this study of whom 116 had undergone Phaco and 34 CECCE. The data of pre- and post-operative ophthalmic examination were not always complete. The numbers of patients can be deduced from Tables 1,2 and 3 .

Pre- and post operative vision. The pre-operative visual acuity was significantly lower in the CECCE group than in the Phaco group ( $p=0.006$ ) (Fig. 1 , Table 1). The difference in visual acuity between both groups could be explained by the fact that patients with mature and hypermature cataracts were in general operated with the CECCE technique. To reduce the difference in preoperative visual acuity in both groups, patients were selected with 
Table 3. The mean post-operative astigmatism on day 1 , day 10 and week 6 in the Phaco and CECCE group

\begin{tabular}{llll}
\hline & PHACO (n) & CECCE (n) & $p$-value \\
\hline Day 1 & $1.836(96)$ & $3.607(21)$ & 0.001 \\
Day 10 & $1.636(81)$ & $3.575(20)$ & 0.004 \\
Week 6 & $1.117(47)$ & $2.382(19)$ & 0.009 \\
\hline
\end{tabular}

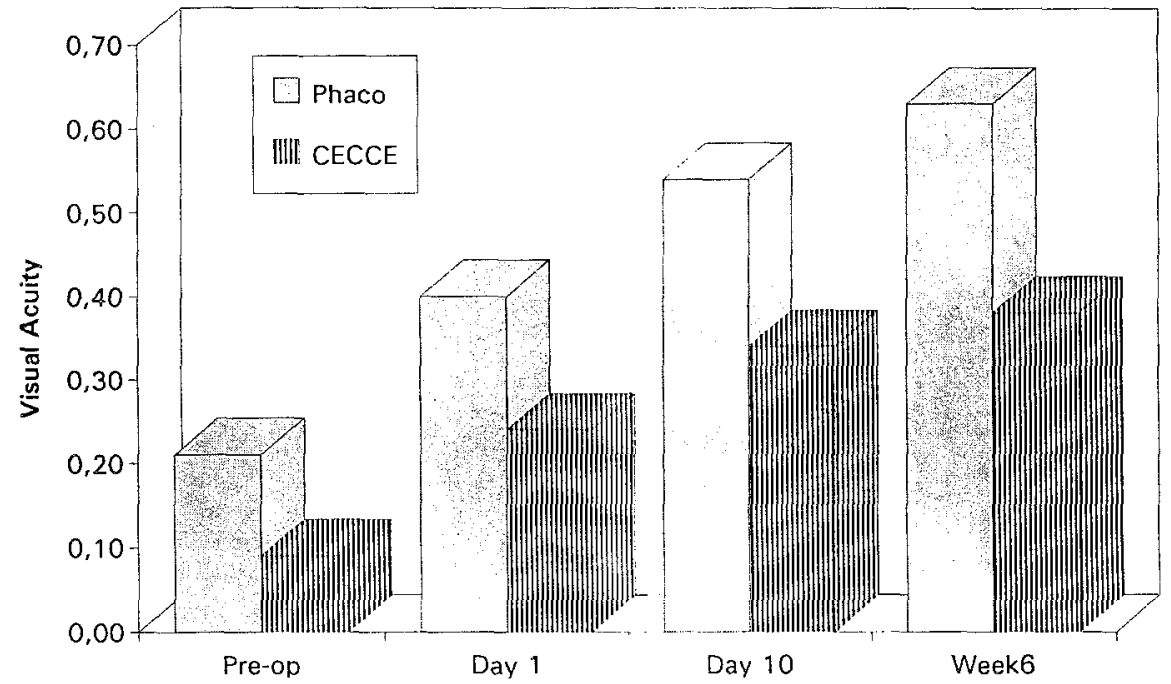

Fig. 1 . The (log) mean pre- and post-operative visual acuity in the Phaco and CECCE group.

a visual acuity $>0.1$. With this selection no significant difference existed in the pre-operative visual acuity between the Phaco group and the CECCE group (Fig. 2). The post-operative mean visual acuities after 1 day and after 10 days, were better in the Phaco group than in the CECCE group $(p=0.02$ and $p=0.015$ ). However, after 6 weeks post-operatively, the difference was reduced ( $p=0.191$ ) (Fig. 2, Table 2).

Post-operative astigmatism. The keratometry values were significantly lower at day 1, day 10 and in week 6 using Phaco than using CECCE (Fig. 3, Table $3)$.

IOL calculation. The average emmetropizing power of the lens was $21 \mathrm{D}$, which should give a predicted refractive power of $-0.5 \mathrm{D}$. However at 6 


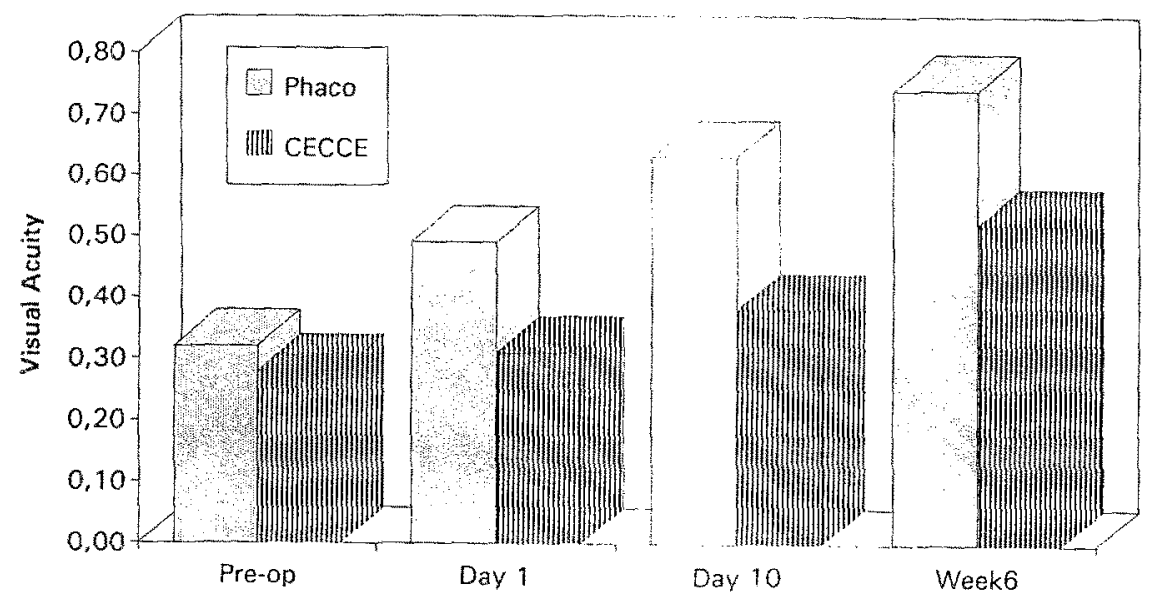

Fig. 2. The (log) mean pre- and post-operative visual acuity in the Phaco and CECCE group after selection of patients with a better visual acuity pre-operatively than 0.1 .

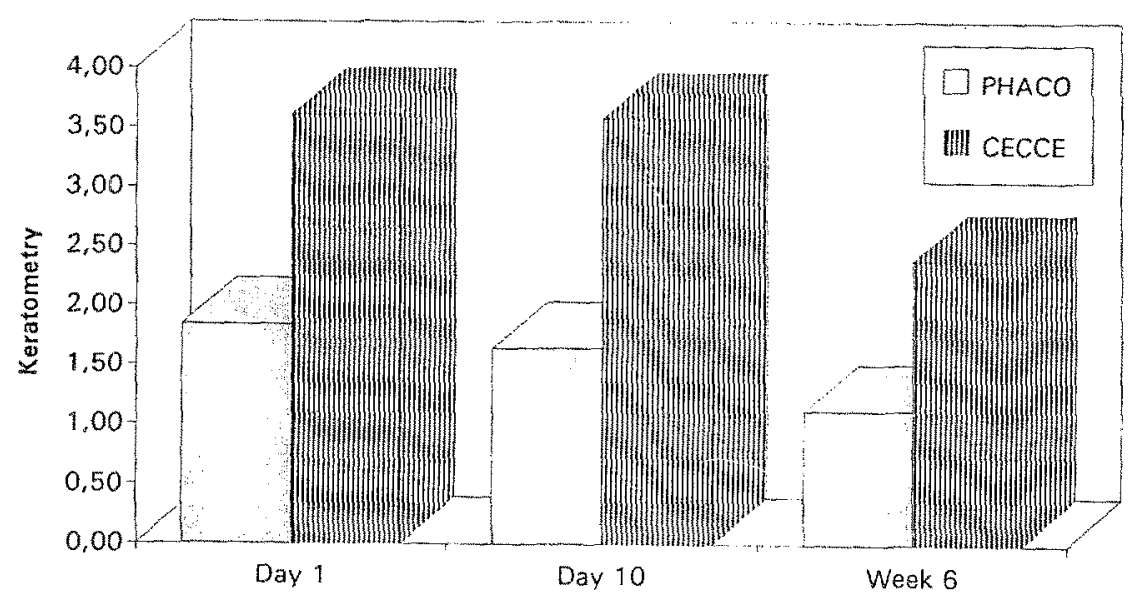

Fig. 3. The mean post-operative astigmatism on day 1, day 10 and week 6 in the Phaco and CECCE group.

weeks post-operatively the resulting refractive power was $-0.88 \mathrm{D}$, thus giving a refractive error of -0.31 (Table 4). The refractive errors according to axial length are summarized in Table 5. The refractive error was inversely proportional with the axial length. 
Table 4. Predicted and resulting refractive error

\begin{tabular}{llll}
\hline & Average & Min & \multicolumn{1}{c}{ Max } \\
\hline 1. Pre-operative refraction (SE): & -1.2987 & +6.0 & -22.9 \\
2. Average lens power: & $21 \mathrm{D}$ & $2 \mathrm{D}$ & $32 \mathrm{D}$ \\
3. Predicted refraction (SE): & -0.521 & +3.7 & -6.23 \\
$\quad(\mathrm{n}=143)$ \\
$\begin{array}{c}\text { 4. Resulting refraction (SE): } \\
\quad(\mathrm{n}=118)\end{array}$ & -0.884 & +3.0 & -7.8 \\
$\begin{array}{c}\text { 5. Resulting - predicted } \\
\text { refraction }(\mathrm{n}=117)\end{array}$ & -0.309 & +1.21 & -2.96 \\
\hline
\end{tabular}

Table 5. Post-operative refractive error by axial length

\begin{tabular}{lllll}
\hline $\begin{array}{l}\text { Axial Length } \\
(\mathrm{mm})\end{array}$ & $\mathrm{n}$ & Refractive error & $>2 \mathrm{D}$ & $>1 \mathrm{D}$ \\
\hline$<20$ & 0 & & & \\
$20-21$ & 3 & -1.893 & $1 / 3$ & $3 / 3$ \\
$>21-22$ & 13 & -0.878 & $1 / 13$ & $5 / 13$ \\
& & & $(7.7 \%)$ & $(38.4 \%)$ \\
$>22-24.5$ & 80 & -0.307 & $2 / 80$ & $18 / 80$ \\
& & & $(2.5 \%)$ & $(22.5 \%)$ \\
$>24.5$ & 21 & -0.058 & $0 / 21$ & $2 / 21$ \\
& & & & $(9.5 \%)$ \\
\hline total & 117 & -0.309 & $4 / 117$ & $28 / 117$ \\
& & & $(3.4 \%)$ & $(23.9 \%)$
\end{tabular}

\section{Discussion}

The patients operated with Phaco in this study had less post-operative corneal astigmatism than those with CECCE during at least the first six weeks postoperatively. The lower post-operative corneal astigmatism observed in the Phaco group was most probably due to the smaller incision $[1,2]$.

Furthermore it was found that for patients operated with Phaco, the visual acuity recovered faster than for patients operated with CECCE. However, the difference between Phaco and CECCE is not significant at 6 weeks. We expect the visual acuity probably to be similar in course of time. A prolonged follow-up is necessary to assess the long-term effects of Phaco. 
Interpretation of the results of the post-operative visual acuity and astigmatism at 6 weeks is difficult due to loss to follow-up, especially in the Phaco group, probably caused by the fact that patients with a good vision at 6 weeks may not respond to the 6 weeks examination. Inclusion of these data would probably result in a better mean log visual acuity and lower astigmatism at 6 weeks in the Phaco group. This would make the significance even more stronger.

The difference between the predicted refractive error and the ultimate result lies within the accepted standard which is 5\%>2 D and $25-30 \%>1 \mathrm{D}$ $[3,4]$. The calculation of IOL power using the Colenbrander formula results in refractive errors, predominantly in eyes with shorter axial lengths. The standard anterior chamber depth, which is used in the Colenbrander formula, is $4.7 \mathrm{~mm}$. Therefore in short eyes, the intraocular lens is implanted relatively nearer to the cornea than in long eyes and this results in myopia. This problem could be solved by correcting the predicted post-operative refraction for the depth of the anterior chamber with a regression curve by axial length and post-operative refraction error for a large group of cataract patients.

This study indicates that Phacoemulsification results in lower corneal astigmatism following intraocular lens implantation and earlier recovery of visual function than extracapsular cataract surgery.

\section{References}

1. Watson A, Sunderraj P. Comparison of small - incision Phacoemulsification with standard extracapsular cataract surgery: post-operative astigmatism and visual recovery. Eye 1992; 6: 626-629.

2. Lindstrom RL, Destro MA. Effect of incision size and Terry keratometer usage on postoperative astigmatism. Am Intraocul Implant Soc J 1985; 11: 469-73,

3. Thijssen JM, Boerrigter RMM. Ultrasonic biometry for lens implantation: analysis of systematic errors. In: Ossoinig KC. ed. Ophthalmic Echography. Martinus Nijhoff/ Dr W. Junk Publishers, Dordrecht, The Netherlands, 1987.

4. Ascaso FJ, Castillo JM. A comparative study of eight intraocular lens calculation formulas. Ophthalmologica 1991; 203: 148-53.

5. Holladay JT, Prager ThC. Mean visual acuity. Am J Ophthalmol 1991; 111: 372-374.

Address for correspondence: G. P. M. Luyten, University Hospital Rotterdam, Department of Ophthalmology, Dr. Molewaterplein 40,3015 GD, Rotterdam, The Netherlands

Phone: 31-10-4633691; Fax: 31-10-4635105 